\title{
In-Vitro Comparison of Antifungal Activity of Herbs (Darehald and Pomegranate) with Azoles
}

\author{
Rabeea Rizwan'1, Shehla Shaheen ${ }^{1}$, Zahida Memon'1, Faisal Afridi' ${ }^{2}$, Mubarak Zaib² \\ ${ }^{1}$ Department of Pharmacology, Ziauddin Medical College, Karachi, Pakistan \\ ${ }^{2}$ Department of Microbiology, Ziauddin University Hospital, Karachi, Pakistan \\ Email:rabeea_rizwan@hotmail.com,drshel2011@gmail.com
}

How to cite this paper: Rizwan, R., Shaheen, S., Memon, Z., Afridi, F. and Zaib, M. (2018) In-Vitro Comparison of Antifungal Activity of Herbs (Darehald and Pomegranate) with Azoles. International Journal of Clinical Medicine, 9, 703-715. https://doi.org/10.4236/ijcm.2018.99059

Received: August 22, 2018

Accepted: September 15, 2018

Published: September 18, 2018

Copyright $\odot 2018$ by authors and Scientific Research Publishing Inc. This work is licensed under the Creative Commons Attribution International License (CC BY 4.0).

http://creativecommons.org/licenses/by/4.0/

\begin{abstract}
Aim: Candida, an opportunistic organism is one of the commonest causes of hospital acquired infections among fungi. Currently available antifungal drugs have numerous adverse effects and drug-drug interactions (DDIs) along with increase in resistance over the time. Therefore, it is highly emergent to consider alternative treatments for candidal infections, having fewer adverse effects and is cost-effective. The current in-vitro study is undertaken to assess and compare the antifungal effects of the herbs, Berberis aristata ( $B$. aristata, Darehald/Darhald) and Punica granatum (P. granatum, Pomegranate) with fluconazole and voriconazole, based on culture and sensitivity of candidal isolates. Materials and Methods: Ethanolic extracts of herbs (Berberis aristata and Punica granatum) and concentrations were formulated as per standard procedure. 130 samples were obtained for the study from in and out patients reported in clinical subsets of Ziauddin Hospital, Karachi from March to May, 2018. Samples were collected and grown according to the standard procedures like, wet mount test and gram's staining. Species were identified by CHROM agar candida and API 20 C AUX methods. Sensitivity tests were performed by Kirby Bauer's disc diffusion method according to CLSI guide lines M-44 A2, 2009. Data analysis was done by one-way ANOVA to compare the antifungal activities of drugs and herbs. Results: Mean inhibitory zones of herbs, $B$. aristata and $P$. granatum were highly significant against clinical candidal isolates with respective p-values of 0.00 and 0.02 . Both of the herbs, $B$. aristata and $P$. granatum were found to be more sensitive, $98.5 \%$ and $97.7 \%$ respectively in comparison to fluconazole showing $42.3 \%$ and voriconazole showing $29.2 \%$ sensitivity against candidal isolates. The most resistant candidal specie was $C$. tropicalis that showed resistance against both fluconazole and voriconazole, contrary to that, this
\end{abstract}


specie was highly sensitive to both of the herbs, showing sensitivity of 100\% respective for Darehald and Pomegranate. Conclusion: In comparison to azoles: Culture sensitivity of both herbs (B. aristata and P. granatum) displayed more sensitivity against candidal isolates of patients having non-invasive and invasive candidiasis. These herbs can be considered as substitute or alternative antifungal agents to the conventional antifungal therapy, particularly in cases of treating candidemia patients, which is a life threating condition.

\section{Keywords}

Candida, Fungi, Azoles, Antifungal Sensitivity, Antifungals, Berberis aristata, Punica granatum, Pomegranate, Darhald, Darehald

\section{Introduction}

The use of herbs in folk medicine has been practiced by humans since ancient times. The traditional herbal therapy is considered as a "shotgun approach" because of multiple constituents of a herb's extract, having many therapeutic mechanisms of actions which result in greater therapeutic activity against various diseases [1]. It is estimated by WHO that around $80 \%$ of world's population rely on natural herbal treatments for their primary cure, mainly in developing world [1] [2]. In the field of ethnobotanic studies, unpurified herbal extracts considered to be safer and more potent as they contain multiple constituents having synergistic activity to achieve required therapeutic effects along with reduced toxicity in comparison to its isolated buffered ingredients [3].

Globally, the frequency of fungal infections is increasing just like bacterial infections [4] [5]. Among fungal infections, candidiasis is one of the common opportunistic organisms related to yeast family [6]. It is responsible for $70 \%$ of all hospital acquired mycological infections [7] [8]. In the field of medicine, till date synthetic drugs are considered as conventional empirical therapy for the treatment of fungal infections. About 18 antifungal drugs were synthesized and approved by authorities from 1980 to 2002 in which majority (83\%) of the drugs were related to the azoles class [9]. For candidiasis, the preference of antifungal therapy depends up on type, nature and extent of the lesion along with patient's generalized health and immune status [10]. Besides, numerous drug-drug interactions, the adverse effects of antifungal drugs are hepatotoxicity, nephrotoxicity, headache, altered taste sensation, anemia, GI upsets, hair loss etc. [11] [12]. Nowadays, the rising resistance to antifungals and cross resistance among its azole class of drugs is a big threat which shows variation topographically [13] [14]. These ground realities are sufficient for the motivation of researchers to consider and evaluate new antifungal drugs or alternative agents for the treatment of candidal infections, showing promising results with better 
efficacy, lower resistance, fewer adverse effects and affordability of the patients [15].

Therefore, this current study was undertaken to evaluate and compare the anticandidal effects of herbs Punica granatum (Pomegranate) peels and Berberis aristata (Darehald) root bark with commonly used azoles (fluconazole and voriconazole) antifungal drugs. The aforementioned herbs are commonly grown and available in regions of Asia [16] [17]. They are used in folk medicine for many therapeutic purposes, Darehald (Darhald) has been used as an antimicrobial, antipyretic, antioxidant, antihypertensive, anti-osteoporotic and anti-arrhythmic herb [18] [19]. Its root and stem barks extracts have potent antipyretic, antimalarial and antimicrobial effects [20] [21]. In the past, pomegranate was popularly called as a "fruit of dead" by Greek mythologists [22]. It is an extensively studied plant in the field of pharmacotherapeutics, having antimicrobial, neuroprotective and immune modulating properties, also being used in treating diabetes mellitus, infantile brain ischemia, weight gain, Alzheimer's disease and arthritis [20] [23]. Regarding toxicity of herbs, Berberis was studied as safe drug with no mortality and hepatoprotective effects in therapeutic doses of even $2000 \mathrm{mg}$ [24] [25] [26]. P. granatum (Punica granatum) was also reported to be safe with no noxious effects at therapeutic doses $<2000 \mathrm{mg}$ daily along with hepatoprotective and nephroprotective effects [23] [27]. It is known as "superfood" by the mythologists because of its apparent non-toxic, curative and probable nutritious values [28].

\section{Materials and Methods}

\section{Study settings:}

Total 1020 samples were collected from in and out-patients of different wards, private rooms, operation theaters, emergency, coronary and intensive units of Dr. Ziauddin group of hospitals (Clifton, Kemari, Ziauddin Memorial and North Nazimabad Ziauddin Hospitals Karachi). All samples were transported within 24 hours to microbiology laboratory of North Nazimabad hospital where the bench work was performed.

\section{Data Analysis:}

The numerical data (mean zone of inhibitions and \pm standard deviations) of herbs (B. aristata and P. granatum) and azoles (fluconazole and voriconazole) were observed and compared by applying one-way analysis of variance (ANOVA) test through a statistical software programanalysis, SPSS $21.95 \%$ confidence interval was taken with p-value less than 0.05 was considered to be significant. While sensitivity and resistance pattern of these variables (herbs and azoles) was evaluated by percentage.

\subsection{Preparation of Crude Extracts}

All herbs were bought from a registered herb dealer, cleaned, dried and stored at room temperature. These herbs were authenticated and placed in herbarium of 
Pharmacognosy department of Jinnah Sind Medical University (JSMU). They were grinded in electric grinder [29] [30]. The powder of each herb was placed in a glass container to mix and soak with the absolute (100\%) ethanol at 3:10 ratio for 20 days. These extracts were filtered by using Whatmann No. 1 filter paper (Figure 1(a) and Figure 1(b)) [4] and further extracted by a rotary evaporator (BUCHI, Switzerland) (Figure 1(c)) [31]. These crude extracts were placed open in ventilated laboratory to let them dry for 7 to 8 days and stored in airtight bottles. [32] [33]. The minimum inhibitory concentrations (MICs) of Berberis aristata $(25 \mathrm{mcg})$ and Punica granatum $(20 \mathrm{mcg})$ extracts were made with per $\mathrm{ml}$ of $5 \%$ Tween 20 [31].

\subsection{Culture Assays Procedure for Yeast Sensitivity Testing}

After approval from the institutional ethical committee, and written informed consent, the 130 (out of 1020) samples of the patients from suspected infected urine, pus, wound, vagina, tracheal aspirates and body fluids (ascitic, peritoneal and pleural fluids), nasogastric tube, incubate tips and blood was taken. Those suspected samples with positive sign and symptoms of infection (e.g. itchy subcutaneous regions of mouth etc., white velvety lesions and history of chronic fatigue, fever and recurrent infections) were identified candidal positive by the following procedure which was processed according to standard microbiological technique. The isolates of Candidal species from clinical samples of vagina, tracheal aspirate, pus, wound, body cavity fluids, sputum, urine, tips and blood identified by Wet mount (for vaginal swabs) (Figure 2(a)), Gram's stain (Figure 2(b)) and Germ tube test (for sputum specimens) (Figure 2(c)) and BACTEC 9240 system (Automated Blood Culture Systems, for candidemia samples) according to microbiological standard procedure. These isolates further identified on the species level by using CHRO Magar Candida (Oxoid Ltd., UK) (Figure 2(d)), and API 20 C AUX test [4] [34]. For screening purpose, simple discs soaked in $200 \mu \mathrm{L}$ of each extract for 37 hours. Modified Kirby Bauer's disc diffusion method (Figure 3) at $0.5 \mathrm{McF}$ arland turbidity was applied as per CLSI M-44 A2series guidelines, 2009 [35] [36] [37]. Muller Hilton Agar (MHA, Oxoid Ltd. UK) was prepared by adding $2 \%$ glucose and $0.5 \mu \mathrm{g} / \mathrm{ml}$ methylene blue in it. Fluconazole (SD 232, $25 \mathrm{mcg} / \mathrm{disc}$ ) and voriconazole (SD 277, $1 \mathrm{mcg} / \mathrm{disc}$, HiMedia, India) discs were placed on MHA and incubated at $35^{\circ} \mathrm{C}$ for 37 hours [17] [38]. The inhibitory zones of samples $>14 \mathrm{~mm}$ for fluconazole $(25 \mathrm{mcg})$ and $>17 \mathrm{~mm}$ for voriconazole ( $1 \mathrm{mcg}$ ) were considered sensitive, as per standard by CLSI M 444-S3 guidelines, 2009 [39] [40] [41]. To the best of our knowledge the cut off values for herbs' (B. aristata and P. granatum) inhibitory zones (ZIH) were not mentioned in any of the previous studies and thus a pilot study wasconducted on 20 candidal samples in order to calculate the cut offs for the inhibitory zones of $B$. aristata and $P$. granatum which were found to be greater than 12 and $8 \mathrm{~mm}$ respectively. All the tests were repeated and confirmed three times [4]. 


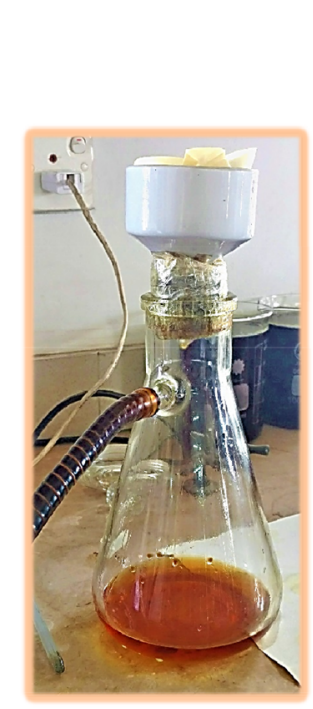

(b)

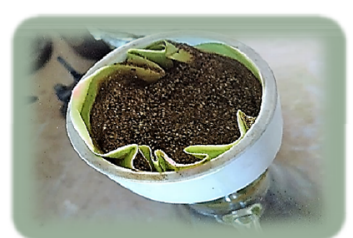

(a)

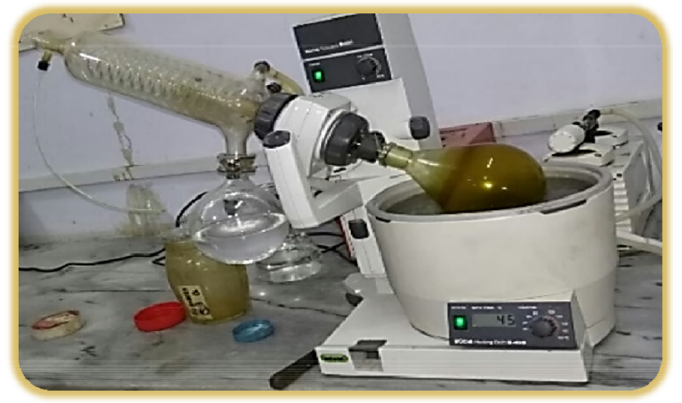

(c)

Figure 1. (a): Filtration of soaked pomegranate ethanolic extract by Whatmann number 1, filter paper. (b): Residual pomegranate coarse powder after filtration of its soaked ethanolic extract. (c): Final herb's (darehald/darhald) extraction by vacuum evaporator.

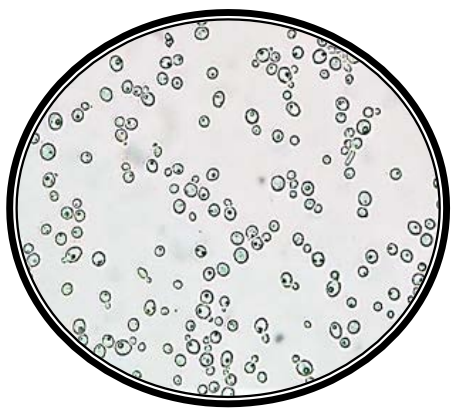

(a)

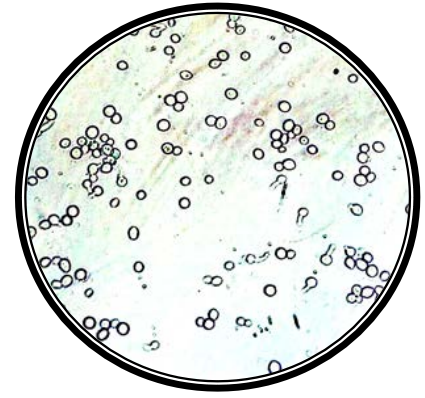

(c)

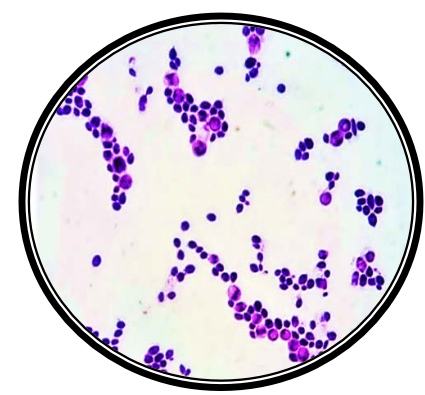

(b)

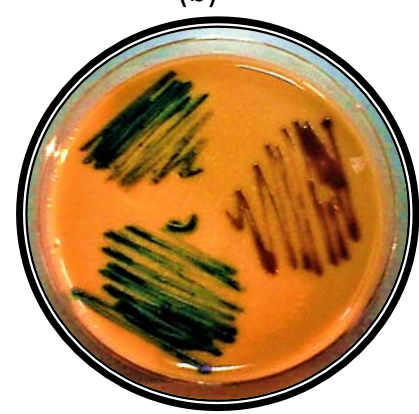

(d)

Figure 2. (a): Microscopic view of a candida positive wet mounted slide of a high vaginal swab specimen. (b): Microscopic view of a clinical specimen showing candidal positive on Gram stain. (c): Microscopic view of a clinical specimen showing candida positive germ tube test. (d): Candidal specie identification of different candidal positive specimens on CHROMEagar media showing colonies of $C$. albicans (green color) and $C$. glabrata (pink/mergenda color). 


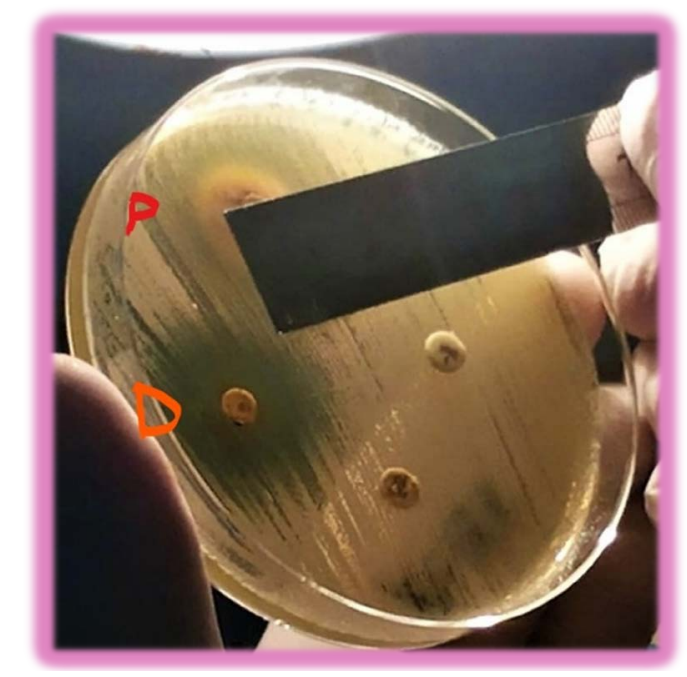

Figure 3. Measuring of inhibitory zones around both herbs (B. aristata and P. granatum) in azole (fluconazole and voriconazole) resistant strain.

\section{Results}

In this current study two herbs, darhald and pomegranate were evaluated for in-vitro antifungal activity against candidal isolates to assess their effectiveness in our clinical set ups. The inhibitory zones of azoles (fluconazole and voriconazole), Berberis aristata (B. aristata, darhald/darehald) and Punica granatum ( $P$. granatum, pomegranate) peels' extracts against candidal strains measured in millimeters $(\mathrm{mm})$. The highest mean zone of inhibition $(\mathrm{ZIH})$ calculated on candidal samples was $22.27 \pm 4.9 \mathrm{~mm}$ of $B$. aristata with statistically significant p-value $<0.05$ while the least $\mathrm{ZIH}$ was $14.29 \pm 12.86$ of fluconazole with p-value $>0.05$, shown in Table 1 . Though according to culture sensitivity pattern of clinical candidal isolates, $B$. aristata was the most sensitive antifungal agent $98.5 \%$ and the least sensitive agent was voriconazole $29.2 \%$, displaying in Table 2.

The candidal species identified from clinical specimens were Candida albicans (C. albicans, 104), Candida tropicalis (13), Candida glabrata (12) and Candida ciferrii (1). While the sensitivity of antifungal agents identified for these various candidal species was; B. aristata - C. albicans 103 (99.03\%), NCACS 25 (98.16\%), P. granatum - C. albicans 101 (95.5\%), NCACS 26 (100\%), fluconazole - C. albicans 43 (37.85\%), NCACS 16 (62.01\%) and voriconazole - C. albicans 31 (30.15\%), NCACS 13 (51\%) as showing in Figure 4.

These results displayed $C$. tropicalis as the least sensitive among identified species, showing sensitivity of $30.55 \%$ (69.45\% resistant) to fluconazole and $5.55 \%$ sensitive ( $94.45 \%$ resistant) to voriconazole (Figure 4 ).

\section{Discussion}

Nowadays herbs are gaining popularity across the globe and are a focus of interest in the field medicine and ethnobotany. Evidence based researches are playing 
Table 1. Mean zone of inhibitions of herbs and azoles on candidal isolates.

\begin{tabular}{cccc}
\hline \multirow{2}{*}{ S. No. } & Drugs/Herbs (MIC in mcg) & Zone of inhibitions $(\mathrm{mm})$ & \multirow{2}{*}{ P-value } \\
\cline { 3 - 3 } & & Mean \pm Std. Deviation & \\
\hline $\mathbf{1}$ & Fluconazole (25) & $14.29 \pm 12.86$ & 0.434 \\
$\mathbf{2}$ & Voriconazole (1) & $16.90 \pm 13.92$ & 0.648 \\
$\mathbf{3}$ & Berberis aristata (25) & $22.27 \pm 4.93$ & $0.000^{*}$ \\
$\mathbf{4}$ & Punica granatum (20) & $17.48 \pm 4.03$ & $0.020^{*}$ \\
\hline
\end{tabular}

P-value calculated by one-way ANOVA followed by Post Hoc Tukey test. ${ }^{*}$-value is significant $(<0.05)$.

Table 2. Sensitivity pattern of azole antifungal drugs and herbs against clinical candidal isolates.

\begin{tabular}{ccccc}
\hline & $\begin{array}{c}\text { Fluconazole } \\
\text { N (\%) }\end{array}$ & $\begin{array}{c}\text { Voriconazole } \\
\text { N (\%) }\end{array}$ & $\begin{array}{c}\text { B. aristata } \\
\text { N (\%) }\end{array}$ & $\begin{array}{c}\text { P. granatum } \\
\text { N (\%) }\end{array}$ \\
\hline Sensitive & $55(42.3)$ & $38(29.2)$ & $125(98.5)$ & $124(97.7)$ \\
Resistant & $75(57.7)$ & $92(70.8)$ & $5(3.8)$ & $6(4.6)$ \\
\hline
\end{tabular}

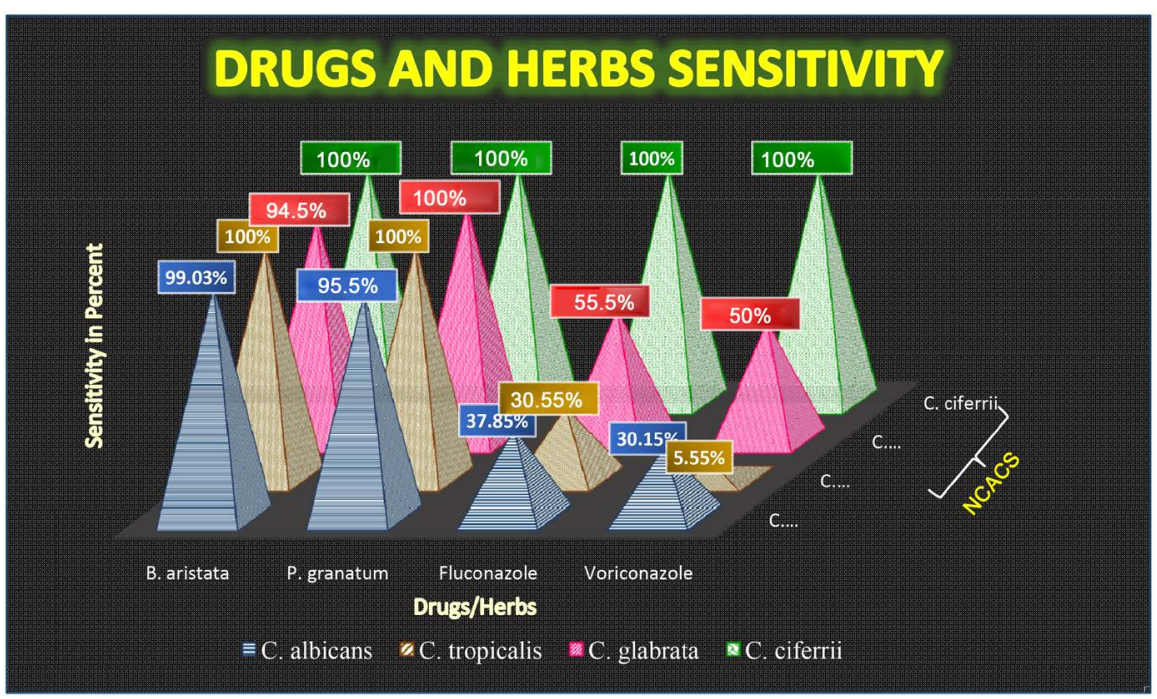

Figure 4. Antifungal sensitivity of azoles and herbs among candida albicans and Non-candida albicans (NCACS).

a crucial role in the exploration and development of new therapeutics [42] The limitations of recently available antifungal drugs, their rise in resistance along with recurrence in fungal (candidal) infections have emphasized the researchers to explore novel antifungal therapies with unique mode of actions against pathogens as well as have few adverse effects, inexpensive and easily available [9]. Since their discovery, azoles (fluconazole and voriconazole) are most widely prescribed antifungal drugs around the world and are fungicidal for aspergillus but are fungistatic for candida with subsequent rise in its resistance over the time [43]. Hence in the current study, two herbs were compared with two most commonly used antifungal drugs of class azoles, fluconazole and voriconazole on the basis of their zones of inhibition for various candidal strains isolated in 
order to know their effectiveness in our community.

In our study, the most sensitive agent on in-vitro culture sensitivity of candidal clinical specimens was $B$. aristata with mean ZIH of $22.27 \pm 4.93 \mathrm{~mm}$ (Table 1 and Table 2). Similarly, a study conducted on $B$. aristata displayed mean ZIH $20.1 \pm 0.15 \mathrm{~mm}$ on candida samples [44]. It is well documented that antifungal activity of B. aristata is mainly due to its alkaloid constituent known as "Berberine" that inhibits fungal cell wall, ergosterol biosynthesis and mitochondrial functions. Interestingly it has been evaluated innocuous to human being cells [45]. According to our results shown in Table 1, the second highest mean inhibitory zone $(17.48 \pm 4.03 \mathrm{~mm})$ against candidal strains was shown by $P$. granatum. This is in accordance to an Indian study in which pomegranate displayed $13 \pm 1.225 \mathrm{~mm}$ of ZIH on candida samples [46]. The antifungal activity of pomegranate's peels ( $P$. granatum) is due to its alkaloid content, tannins containing punicalagin, granatins $\mathrm{A}$ and $\mathrm{B}$, gallagyldilacton, casuarinin, pedunculagin, tellimagrandin I and corilagin. These constituents cause fungal cell wall alteration, inhibition of candidal cells' habitation, dwelling and growth on host [47] [48]. In our study the sensitivity of both herbs, B. aristata and $P$. granatum for candidal isolates were shown to be $98.5 \%$ and $97.7 \%$ receptively which was greater than both azoles (Table 2). To the best of our knowledge our study is innovative as we reported and compared for the first time the sensitivity pattern of the herbs for candidal samples as in the previous studies only mean zone of inhibitions were mentioned, which already have been discussed above. While the mean inhibitory zones of azoles noticed in this current study were $14.29 \pm 12.86$ $\mathrm{mm}$ for fluconazole and $16.90 \pm 13.92 \mathrm{~mm}$ for voriconazole with $42.3 \%$ sensitivity to fluconazole (57.7\% resistance), and sensitivity to voriconazole was $29.2 \%$ (70.8\% resistance). These results are comparable with global surveillance data by Pfaller, 2010 reported sensitivity of $90.2 \%$ (6.2\% resistant) to fluconazole and 95\% (3\% resistance) to voriconazole [48]. In the current research resistance pattern of fluconazole among species noted was, C. tropicalis $69.45 \%$, C. glabrata $11.1 \%$ and $C$. albicans $62.15 \%$ while for voriconazole the resistance was shown for C. tropicalis $94.45 \%$, C. albicans $69.85 \%$, C. glabrata 50\% (Figure 1). Our results clearly displayed that among all isolated candidal species the most resistant specie was C. tropicalis with respective $69.45 \%$ and $94.45 \%$ resistance against both fluconazole and voriconazole. Contrasting results were reported by Pfaller where the highest resistance to fluconazole was observed for C. glabrata, 15.7\% followed by $C$. tropicalis $4.1 \%$ and $C$. albicans $1.4 \%$ while for voriconazole the resistance shown was C. glabrata $10 \%$, C. tropicalis $5.4 \%$ and C. albicans $1.2 \%$ [49]. A study conducted in Iran also displayed contradictory results to our study; the most resistant specie to fluconazole was $C$. glabrata $79.1 \%$ though similar to our study the most resistant specie was $C$. tropicalis showing $41.6 \%$ resistance against voriconazole [50]. We hoped that the results of this current study may benefit clinicians to recommend appropriate antifungal drugs according to the culture and sensitivity patterns of the candidal isolates prevalent in our community. This current study also highlighted the role of commonly available herbs as 
alternative treatment for candidal infection even for those showing high level of resistance to azoles.

\section{Conclusions}

Punica granatum and berberis aristata exhibited superior antifungal activity on all cultured samples of candida in comparison to two widely prescribed azoles, fluconazole and voriconazole in our population. To the best of our knowledge the current study is the first one to report sensitivity patterns of the B. Aristata and $P$. granatum on candidal isolates. $C$. tropicalis was greatly resistant to both of the azoles but in contrast, our studied herbs, B. aristata and $P$. granatum showed remarkable sensitivity for all candidal species including even those species showing high resistance to both of the commonly prescribed azoles, fluconazole and voriconazole.

Furthermore, both herbs are economical, easily available and documented to have better safety profiles with health boosting properties in general. While conventional antifungal drugs have lots of side effects including drug-drug interactions and are not cost-effective. Hence it is highly recommendable that both herbs, $B$. aristata and $P$. granatum can be considered as alternative drugs for the treatment of candidiasis in near future after subsequent clinical trials and further verification of our results.

\section{Limitations of the Study}

We conducted our study in few tertiary care health centers of only in one city (Karachi) of our country and could not include other cities and rural areas due to a limited budget.

\section{Conflicts of Interest}

The authors declare no conflicts of interest regarding the publication of this paper.

\section{References}

[1] Carmona, F. and Pereira, A.M.S. (2013) Herbal Medicines: Old and New Concepts, Truths and Misunderstandings. Revista Brasileira de Farmacognosia, 23, 379-385. https://doi.org/10.1590/S0102-695X2013005000018

[2] Verma, S. and Singh, S. (2008) Current and Future Status of Herbal Medicines. Veterinary World, 1, 347-350. https://doi.org/10.5455/vetworld.2008.347-350

[3] Pal, S.K. and Shukla, Y. (2003) Herbal Medicine: Current Status and the Future. Asian Pacific Journal of Cancer Prevention, 4, 281-288.

[4] Zafar, S., Khurram, M., Usman, R., Khan, F. and Nasim, R. (2015) Clotrimazole, Fluconazole, Ketoconazole and Itraconazole Susceptibilities of Candida Species in Vulvovaginitis. Cell, 342, Article ID: 9766463.

[5] Nucci, M. and Lyon, S. (2014) Conference Report from the 6th Trends in Medical Mycology Meeting, Copenhagen, 11-14 October 2013: Facing the Global Threat of Fungal Disease. Current Fungal Infection Reports, 8, 116-118. https://doi.org/10.1007/s12281-014-0173-2 
[6] Meiller, T.F., Hube, B., Schild, L., Shirtliff, M.E., Scheper, M.A., Winkler, R. and Jabra-Rizk, M.A. (2009) A Novel Immune Evasion Strategy of Candida albicans. Proteolytic Cleavage of a Salivary Antimicrobial Peptide. PLOS ONE, 4, e5039. https://doi.org/10.1371/journal.pone.0005039

[7] Aslam, A., Akhtar, N., Hasan, F. and Shah, A.A. (2015) Prevalence and in Vitro Antifungal Susceptibility Pattern of Candida Species in a Tertiary Care Hospital, Rawalpindi, Pakistan. Pakistan Journal of Zoology, 47, 335-342.

[8] Azie, N., Neofytos, D., Pfaller, M., Meier-Kriesche, H.-U., Quan, S.-P. and Horn, D. (2012) The PATH (Prospective Antifungal Therapy) Alliance ${ }^{\circledast}$ Registry and Invasive Fungal Infections: Update 2012. Diagnostic Microbiology and Infectious Disease, 73, 293-300. https://doi.org/10.1016/j.diagmicrobio.2012.06.012

[9] Vengurlekar, S., Sharma, R. and Trivedi, P. (2012) Efficacy of Some Natural Compounds as Antifungal Agents. Pharmacognosy Reviews, 6, 91.

https://doi.org/10.4103/0973-7847.99942

[10] Cannon, R.D., Lamping, E., Holmes, A.R., Niimi, K., Tanabe, K., Niimi, M. and Monk, B.C. (2007) Candida albicans Drug Resistance: Another Way to Cope with Stress. Microbiology, 153, 3211-3217. https://doi.org/10.1099/mic.0.2007/010405-0

[11] Cannon, R.D., Lamping, E., Holmes, A.R., Niimi, K., Baret, P.V., Keniya, M.V. and Monk, B.C. (2009) Efflux-Mediated Antifungal Drug Resistance. Clinical Microbiology Reviews, 22, 291-321. https://doi.org/10.1128/CMR.00051-08

[12] Nett, J.E. and Andes, D.R. (2016) Antifungal Agents: Spectrum of Activity, Pharmacology, and Clinical Indications. Infectious Disease Clinics of North America, 30, 51-83. https://doi.org/10.1016/j.idc.2015.10.012

[13] Perlin, D.S., Shor, E. and Zhao, Y. (2015) Update on Antifungal Drug Resistance. Current Clinical Microbiology Reports, 2, 84-95. https://doi.org/10.1007/s40588-015-0015-1

[14] Van der Linden, J.W.M., Arendrup, M.C., Warris, A., Lagrou, K., Pelloux, H., Hauser, P. M., et al. (2015) Prospective Multicenter International Surveillance of Azole Resistance in Aspergillus fumigatus. Emerging Infectious Diseases, 21, 1041. https://doi.org/10.3201/eid2106.140717

[15] Rathod, T., Padalia, H. and Chanda, S. (2015) The Potential of Plant Extracts against Multidrug Resistant Candida Species: A Review.

[16] Setty, A.R. and Sigal, L.H. (2005) Herbal Medications Commonly Used in the Practice of Rheumatology: Mechanisms of Action, Efficacy, and Side Effects. Seminars in Arthritis and Rheumatism, 34, 773-784. https://doi.org/10.1016/j.semarthrit.2005.01.011

[17] Vandenbossche, I., Vaneechoutte, M., Vandevenne, M., De Baere, T. and Verschraegen, G. (2002) Susceptibility Testing of Fluconazole by the NCCLS Broth Macrodilution Method, E-Test, and Disk Diffusion for Application in the Routine Laboratory. Journal of Clinical Microbiology, 40, 918-921. https://doi.org/10.1128/JCM.40.3.918-921.2002

[18] McMurray, J.J., Adamopoulos, S., Anker, S.D., Auricchio, A., Böhm, M., Dickstein, K. and Gomez-Sanchez, M.A. (2012) ESC Guidelines for the Diagnosis and Treatment of Acute and Chronic Heart Failure 2012. European Journal of Heart Failure, 14, 803-869. https://doi.org/10.1093/eurjhf/hfs105

[19] Yogesh, H., Chandrashekhar, V., Katti, H., Ganapaty, S., Raghavendra, H., Gowda, G.K. and Goplakhrishna, B. (2011) Anti-Osteoporotic Activity of Aqueous Methanol Extract of Berberis aristata in Ovariectomized Rats. Journal of Ethnopharmacology, 134, 334-338. https://doi.org/10.1016/j.jep.2010.12.013 
[20] Ng, K.P., Kuan, C.S., Kaur, H., Na, S.L., Atiya, N. and Velayuthan, R.D. (2015) Candida Species Epidemiology 2000-2013: A Laboratory-Based Report. Tropical Medicine \& International Health, 20, 1447-1453. https://doi.org/10.1111/tmi.12577

[21] Chandra, J., Kuhn, D.M., Mukherjee, P.K., Hoyer, L.L., McCormick, T. and Ghannoum, M.A. (2001) Biofilm Formation by the Fungal Pathogen Candida Albicans: Development, Architecture, and Drug Resistance. Journal of Bacteriology, 183, 5385-5394. https://doi.org/10.1128/JB.183.18.5385-5394.2001

[22] Hirano, R., Sakamoto, Y., Kudo, K. and Ohnishi, M. (2015) Retrospective Analysis of Mortality and Candida Isolates of 75 Patients with Candidemia: A Single Hospital Experience. Infection and Drug Resistance, 8, 199-205. https://doi.org/10.2147/IDR.S80677

[23] Rahmani, A.H., Alsahli, M.A. and Almatroodi, S.A. (2017) Active Constituents of Pomegranates (Punica granatum) as Potential Candidates in the Management of Health through Modulation of Biological Activities. Pharmacognosy Journal, 9, 689-695. https://doi.org/10.5530/pj.2017.5.109

[24] Joshi, P.V., Shirkhedkar, A.A., Prakash, K. and Maheshwari, V.L. (2011) Antidiarrheal Activity, Chemical and Toxicity Profile of Berberis aristata. Pharmaceutical Biology, 49, 94-100. https://doi.org/10.3109/13880209.2010.500295

[25] Mazumder, P.M., Das, S. and Das, M.K. (2011) Phyto-Pharmacology of Berberis aristata DC: A Review. Journal of Drug Delivery and Therapeutics, 1, 46-50. https://doi.org/10.22270/jddt.vli2.34

[26] Di Pierro, F., Putignano, P., Villanova, N., Montesi, L., Moscatiello, S. and Marchesini, G. (2013) Preliminary Study about the Possible Glycemic Clinical Advantage in Using a Fixed Combination of Berberis aristata and Silybum marianum Standardized Extracts versus Only Berberis aristata in Patients with Type 2 Diabetes. Clinical Pharmacology: Advances and Applications, 5, 167-174. https://doi.org/10.2147/CPAA.S54308

[27] Bassiri Jahromi, S., Pourshafie, M.R., Mirabzadeh, E., Tavasoli, A., Katiraee, F., Mostafavi, E. and Abbasian, S. (2015) Punica granatum Peel Extract Toxicity in Mice. Jundishapur Journal of Natural Pharmaceutical Products, 10, e23770. https://doi.org/10.17795/jinpp-23770

[28] Ali, H., Mahmood, N., Trali, G., Qamar, K. and Saga, Z. (2017) Protective Role of Pomegranate Juice and Its Peel Extract on Steroid Induced Raised Serum Creatinine in Mice. Pomegranate Juice and Serum Creatinine Level, 12, 29-34.

[29] Uppuluri, P., Khan, A. and Edwards, J.E. (2017) Current Trends in Candidiasis Candida albicans: Cellular and Molecular Biology. Springer, Berlin, 5-23.

[30] World Health Organization (2014) Antimicrobial Resistance: Global Report on Surveillance.

[31] Shami, A.-M.M., Philip, K. and Muniandy, S. (2013) Synergy of Antibacterial and Antioxidant Activities from Crude Extracts and Peptides of Selected Plant Mixture. BMC Complementary and Alternative Medicine, 13, 360-375. https://doi.org/10.1186/1472-6882-13-360

[32] Kaneria, M.J. and Chanda, S.V. (2013) The Effect of Sequential Fractionation Technique on the Various Efficacies of Pomegranate (Punica granatum L.). Food Analytical Methods, 6, 164-175. https://doi.org/10.1007/s12161-012-9412-8

[33] Amjad, L. and Shafighi, M. (2012) Antioxidant Activity of Leaf Different Extracts in Punica granatum. International Journal of Biological and Medical Research, 3, 2065-2067. 
[34] da Silva, A.R., de Andrade Neto, J.B., da Silva, C.R., de Sousa Campos, R., Silva, R.A.C., Freitas, D.D. and Grangeiro, T.B. (2016) Berberine Antifungal Activity in Fluconazole-Resistant Pathogenic Yeasts: Action Mechanism Evaluated by Flow Cytometry and Biofilm Growth Inhibition in Candida spp. Antimicrobial Agents and Chemotherapy, 60, 3551-3557. https://doi.org/10.1128/AAC.01846-15

[35] Abduljabbar, T., Hussain, M., Adnan, T., Vohra, F. and Javed, F. (2017) Comparison of Oral Candida Species Prevalence and Carriage among Gutka-Chewers and Betel-Quid Chewers. JPMA. The Journal of the Pakistan Medical Association, 67, 350-354.

[36] Gonçalves, B., Ferreira, C., Alves, C.T., Henriques, M., Azeredo, J. and Silva, S. (2016) Vulvovaginal Candidiasis: Epidemiology, Microbiology and Risk Factors. Critical Reviews in Microbiology, 42, 905-927. https://doi.org/10.3109/1040841X.2015.1091805

[37] Wayne, P.A. (2009) Clinical and Laboratory Standards Institute (CLSI) Method for Antifungal Disk Diffusion Susceptibility Testing of Yeasts; Approved Guideline. 2nd Edition, CLSI Document M44-A2.

[38] Shino, B., Peedikayil, F.C., Jaiprakash, S.R., Ahmed Bijapur, G., Kottayi, S. and Jose, D. (2016) Comparison of Antimicrobial Activity of Chlorhexidine, Coconut Oil, Probiotics, and Ketoconazole on Candida albicans Isolated in Children with Early Childhood Caries: An in Vitro Study. Scientifica, 2016, Article ID: 7061587.

[39] Sahoo, S., Mohanty, I., Parida, B. and Patnaik, S. (2018) Prevalence of Vulvovaginal Candidiasis in Sexually Active Females with Antifungal Susceptibility Patterns of the Isolates. International Journal of Clinical and Biomedical Research, 4, 38-41. https://doi.org/10.5455/ijcbr.2018.42.09

[40] Espinel-Ingroff, A., Canton, E., Gibbs, D. and Wang, A. (2007) Correlation of Neo-Sensitabs Tablet Diffusion Assay Results on Three Different Agar Media with CLSI Broth Microdilution M27-A2 and Disk Diffusion M44-A Results for Testing Susceptibilities of Candida spp. and Cryptococcus Neoformans to Amphotericin B, Caspofungin, Fluconazole, Itraconazole, and Voriconazole. Journal of Clinical Microbiology, 45, 858-864. https://doi.org/10.1128/JCM.01900-06

[41] Wayne, P. (2009) Zone Diameter Interpretive Standards, Corresponding Minimal Inhibitory Concentration (MIC) Interpretive Breakpoints, and Quality Control Limits for Antifungal Disk Diffusion Susceptibility Testing of Yeasts. Third International Supplement CLSI Document-M444-S3, New York.

[42] Benzie, I.F. and Wachtel-Galor, S. (2011) Herbal Medicine: Biomolecular and Clinical Aspects. Second Edition, CRC Press, Boca Raton.

https://doi.org/10.1201/b10787-2

[43] Bondaryk, M., Kurzątkowski, W. and Staniszewska, M. (2013) Antifungal Agents Commonly Used in the Superficial and Mucosal Candidiasis Treatment: Mode of Action and Resistance Development. Advances in Dermatology and Allergology, 30, 293-301. https://doi.org/10.5114/pdia.2013.38358

[44] Divya, V.V. and Umamaheswari, S. (2014) Antimicrobial Activity of Selected Herbal Extracts against Multi Drug Resistant Oral Pathogens Isolated from Leprosy $\mathrm{Pa}$ tients. International Journal of Pharmaceutics, 4, 128-132.

[45] Dhamgaye, S., Devaux, F., Vandeputte, P., Khandelwal, N.K., Sanglard, D., Mukhopadhyay, G. and Prasad, R. (2014) Molecular Mechanisms of Action of Herbal Antifungal Alkaloid Berberine, in Candida albicans. PLoS ONE, 9, e104554. https://doi.org/10.1371/journal.pone.0104554

[46] Gowhar, O., Singh, N., Sultan, S., Ain, T., Mewara, A. and Shah, I. (2015) Natural 
Herbs as Alternative to Synthetic Antifungal Drugs-The Future Challenging Therapy. British Biomedical Bulletin, 3, 440-452.

[47] Anibal, P.C., Peixoto, I.T.A., Foglio, M.A. and Höfling, J.F. (2013) Antifungal Activity of the Ethanolic Extracts of Punica granatum L. and Evaluation of the Morphological and Structural Modifications of Its Compounds upon the Cells of Candida spp. Brazilian Journal of Microbiology, 44, 839-848. https://doi.org/10.1590/S1517-83822013005000060

[48] Bassiri-Jahromi, S., Katiraee, F., Hajimahmoodi, M., Mostafavi, E. and Pourshafie, M.R. (2015) In Vitro Antifungal Activity of Various Persian Cultivars of Punica granatum L. Extracts against Candida Species. Jundishapur Journal of Natural Pharmaceutical Products, 10, e19754. https://doi.org/10.17795/jjnpp-19754

[49] Pfaller, M., Diekema, D., Gibbs, D., Newell, V., Ellis, D., Tullio, V., Ling, T., et al. (2010) Results from the ARTEMIS DISK Global Antifungal Surveillance Study, 1997 to 2007: A 10.5-Year Analysis of Susceptibilities of Candida Species to Fluconazole and Voriconazole Determined by CLSI Standardized Disk Diffusion. Journal of Clinical Microbiology, 48, 1366-1377.

[50] Baghdadi, E., Khodavaisy, S., Rezaie, S., Abolghasem, S., Kiasat, N., Salehi, Z., Aala, F., et al. (2016) Antifungal Susceptibility Patterns of Candida Species Recovered from Endotracheal Tube in an Intensive Care Unit. Advances in Medicine. 